\title{
Extracorporeal Shock Wave Lithotripsy for the treatment of ureteral stones : a Critique on Success rate
}

\section{Ayoub Barzegarnezhad, Behzad Feizzadeh Kerigh*, Fariborz Azizi}

Department of Urology, Mazandaran University of Medical Sciences, Sari, Iran

Study Area: Tuba Clinic, Sari, Iran

Coordinate: $36^{\circ} 33^{\prime} 48^{\prime} \mathrm{N}$; $53^{\circ} 03^{\prime} 36^{\prime} \mathrm{E}$

Key words: Gross hematuria, Lithotripsy, Urinary calculi, Pyelonephritis, Urolithiasis

\begin{abstract}
In nowadays Extracorporeal Shock Wave Lithotripsy (SWL) is one of the most accepted and minimally invasive therapeutic options for the treatment of urinary stones. Unfortunately, till date, only a handful studies have regarded the extrusion rate of stones located in the middle and lower part of the ureter via SWL. We evaluated the success rate of this procedure in the treatment of ureteral calculi by conducting a descriptive study carried out through the analysis of the files and radiographs of 191 patients with urolithiasis who underwent lithotripsy.. Success rates were recorded on the basis of the location of stones which were as follows: $89.4 \%$ with urolithiasis in the upper part of the ureter responded to one session of lithotripsy. The success rate in those with calculi located in the middle and the lower part of the ureter was $90.9 \%$ and $88.1 \%$, respectively. Gross hematuria and pyelonephritis were observed in $90.05 \%$ and $2.61 \%$ of patients, respectively.
\end{abstract}

those composed of calcium oxalate monohydrate, cystine, and brushite were resistant to SWL and their fragmentation could not be accomplished using SWL technique (Klee et al., 1991). Furthermore, some stones which should be fragmented under SWL, but failed to fragment completely and due to which the patient requires secondary treatments (Kim et al., 2007). To date, many studies have been conducted in response to the abovementioned issues concerning renal stones and the relevant role of SWL. In the majority of such studies, the effectiveness of SWL in the treatment of nephrolithiasis and stones in the upper part of the ureter was evaluated. However, there are insufficient reports available which could make us understand about the stones located in the middleand lower part of the ureter.

Seeing the importance of the treatment of patients with urinary stones and the necessity for more research focusing on urinary stones as well as the role of SWL in such situations, this study was conducted to evaluate the clinical outcome of urolithiasis treatment via SWL through a descriptive study. The objective of this study was to assess and discuss the success rate of SWL in treating ureteral stones (upper, middle and lower part) among patients referred to the Tuba clinic of the Sari-Iran, affiliated to the Mazandaran University of Medical Sciences, from 2008 to 2013. 


\section{Material and Methods:}

The present study aimed to evaluate the success rate of SWL while the patients were under treatment of ureteral stones particularly those at the lower part of the ureter and the associated complications. It is a retrospective descriptive type of study in which 191 patients who were having stones in their ureters referred to the Tuba clinic for lithotripsy from 2008 to 2013 were considered. The patients suffering from urolithiasis for more than 3 weeks, receiving medical treatment, but desired response was not obtained and/or the patients suffering from acute renal colic were chosen for the study.

The exclusion criteria were pregnancy, uncontrolled hypertension, disorders with active bleeding, active urinary tract infection, heart diseases and urinary stones found in locations other than the ureter. All such patients who underwent SWL (in the various therapeutic sessions of lithotripsy) and possessed a complete set of record were considered for the study. Necessary laboratory testing prior to treatment included complete blood count, urea, creatinine and uric acid measurements, urinalysis and urine culture, blood coagulation tests and pregnancy testing for women who were of childbearing age were done. Individuals with leukocytosis at the time of lithotripsy or other abnormal laboratory results in the tests mentioned above were excluded from the study.

Piezolith-30oo triple focus machine made in Germany by Richard Wolf was employed as the Crusher machine. All the patients were placed in a supine position and 500o6000 mega-pascal shockwaves was utilized as an analgesic at a frequency of 15-18 MHz. Successful treatment was defined as being stone free by ultrasound study, Kidney Ureter Bladder (KUB) or in rare cases Intra Venous Pyelography (IVU). The patients were imaged until the 3 rd month after lithotripsy specifically at the 2 nd week, the end of the first month after SWL and at the end of the zrd month. The patients' follow up by imaging continued until they were found stone free and it was only considered as the case of successful treatment.

Proper Attempt has also been taken for possible statistical analysis to compare the difference but due high variation in the data set, we couldn't get the valid results which could be discussed.

\section{Results:}

In our study, out of 191 patients (122 (63.9\%) male and 69 (36.1\%) female) underwent SWL within a range of $16-85$ years of age group ( $44.28 \pm 14.13$ years). The average weight of the subjects was $72.86 \pm 10.63 \mathrm{~kg}$. Further, only 26 subjects (13.6\%) were noted as hypertensed (HTN), 13 subjects (6.8\%) had diabetes mellitus (DM)., and 15 patients $(7.8 \%)$ was having a positive history of a urinary tract infection (UTI). Among all the subjects, 44 individuals $(23 \%)$ had a history of undergoing transurethral lithotripsy (TUL) the history of the previous
SWL in such patients was also assessed. Only 11 subjects had a prior history of genitor-urinary system surgery. The location of stones in the ureter was another important variable which was recorded as: 47 patients $(24.6 \%)$ had stones in the upper one-third of the ureter, 77 patients (40.3\%) had stones in the middle one-third of the ureter and 67 patients $(35.1 \%)$ had stones in the lower one-third of the ureter. It was observed that 58 stones (30.4\%) were non-opaque in KUB radiographs and 133 stones (69.6\%) were opaque. In total, 26 subjects (13.6\%) took analgesic medication during lithotripsy and 165 subjects (86.4\%) did not take any medication. Interestingly, the success rate of lithotripsy in the first session of SWL (single treatment session) was $89.5 \%$ (171 patients). However, 19 patients (9.9\%) responded to the treatment in the second therapeutic session while 1 patient $(0.5 \%)$ required 3 serial sessions of lithotripsy.

Table-1. Location of the stones in the different parts of the ureter and number of sessions dependent success rate of lithotripsy

\begin{tabular}{llll}
\hline Success rate & \multicolumn{3}{c}{ Locations of the stone } \\
\hline & Upper & middle & Lower \\
Session 1: 171*(89.47\%) & $4^{*}(89.4 \%)$ & $70^{*}(90.9 \%)$ & $59^{*}(88.06 \%)$ \\
Session 2: 19*(95\%) & $5^{*}(100 . \%)$ & $6^{*}(85.71 \%)$ & $8^{*}(100 \%)$ \\
Session 3:1*(100\%) & o & $1^{*}(100 \%)$ & o \\
\hline
\end{tabular}

Table-2. Various physical factors dependent success rate of lithotripsy

\begin{tabular}{llll}
\hline Physical factors & \multicolumn{2}{c}{$\begin{array}{c}\text { Success rate of lithotripsy } \\
\text { Session 1 }\end{array}$} \\
\hline HTN & + & $26^{*}(13.6 \%)$ & $100 \%$ \\
& - & $165^{*}(85.4 \%)$ & $87.9 \%$ \\
\hline Gender & Male & $122^{*}(63.9 \%)$ & $91.8 \%$ \\
& Female & $69^{*}(39.1 \%)$ & $85.5 \%$ \\
\hline DM & + & $13^{*}(6.8 \%)$ & $100.0 \%$ \\
& - & $178^{*}(93.2 \%)$ & $88.8 \%$ \\
\hline History of & + & $44^{*}(23 \%)$ & $10.9 \%$ \\
TUL & - & $147^{*}(77 \%)$ & $89.1 \%$ \\
\hline History of & + & $15^{*}(7.8 \%)$ & $85.7 \%$ \\
recent UTI & - & $176^{*}(92.2)$ & $89.8 \%$ \\
\hline
\end{tabular}

${ }^{*} \mathrm{n}=$ number of individuals (patients)

Nearly $90 \%$ responses to the treatment, defined as stone free was concluded by KUB or sonography, observed in the first session, for convenience we used the results of the first session of SWL for data collection and the success rate based on the location of the stones for comparison. Transient gross hematuria is known to be one of the most common complications after lithotripsy and was observed among 172 subjects (90.05\%) out of the 191 patients in this study. Furthermore, 5 subjects $(2.61 \%)$ were afflicted with pyelonephritis while 14 patients $(7.32 \%)$ did not face any complications. The occurrence of different complications did not relate to the part of the ureter that the stones occurred in. In our record, we found $32.1 \%$ of stones were 
smaller than $10 \mathrm{~mm}, 61.6 \%$ were between $10-20 \mathrm{~mm}$ and $6.3 \%$ were larger than $20 \mathrm{~mm}$. These differences were not statistically significant (p. value $=0.70$ ). But, among the stones that were less than $10 \mathrm{~mm}, 88.52 \%$ disintegrated in the first session of lithotripsy. For mid-size stones, $91.45 \%$ disintegrated in the first session of lithotripsy. For stones greater than $20 \mathrm{~mm}, 75 \%$ disintegrated in the first session of lithotripsy. The success rate of lithotripsy in the different sessions on the basis of various patients factors such as gender, risk factor like DM and HTN and an existence of a history of previous interventions such as surgery and lithotripsyare shown in the table 2.

\section{Discussion:}

Though the SWL is considered as one of the safest technique to remove the stones but few reports suggests that it often fails to remove all the stones (Skolarikos et al., 2006; Ashraf et al., 2010). Earlier reports suggest that the success rate of SWL depends on different factors such as the size of the calculus and burden, stone composition and density, the location of the stone, kidney morphology and congenital abnormalities. Thus, estimating the likelihood of stone clearance for each individual is very important for determining who may get maximum benef it from this favorable procedure (Ashraf et al., 2010).

We found the gender distribution of patients resembles the earlier reports (Wilkinson, 2001; Singh et al., 2010). The mean age of patients was $44.28 \pm 14.13$ years which also testif ied elsewhere (Wilkinson, 2001; Middela et al., 2010). In our study, the number of patients with stones located in the lower part of the ureter who underwent SWL was approximately similar to those with proximal urolithiasis.

The rate of success lithotripsy in the 3 regions of the ureter (upper, middle and lower) was nearly equal and was $\sim 90 \%$. Another notably observed point was that the success rate in the first session of lithotripsy was $89.5 \%$ and only $10.5 \%$ of subjects required additional sessions of treatment. In contrast, some previous studies have reported that successful treatment required more than a single-session lithotripsy (Pearl et al., 2001).

Interestingly, a considerable number of our considered patients with the urinary calculi in the lower segment of their ureters. Many prior studies have reported that calculi located in the lower ureter are refractory to SWL (Miller et al., 1986; Skolarikos et al., 2006). However, our observed success rate was higher than reports of some other studies. Ghimire et al. (2012) found that the number of therapeutic sessions required for complete fragmentation varied from one to four sessions; although, similar to the current study, the majority of their cases $(76.7 \%)$ responded to treatment in a single session, $17.8 \%$ required two sessions and $2.6 \%$ required three or four sessions for complete fragmentation. Among the observed subjects, the mean diameter of the stones in the ureter was
$13.89 \mathrm{~mm}$. Ghimire et al.(2012) reported that the number of sessions needed for lithotripsy increased as the location of the stones moved from proximal part of the ureter to the distal part. Specif ically, 1.11 and 1.71 sessions were required for stones in the upper and lower ureter, respectively (Pearl et al., 2001). However, our study revealed the number of sessions were less and most of the patients responded to one session of lithotripsy only. In the present research, 131 subjects $(68.6 \%)$ were having opaque stones which support reports of Bihl \& Meyers, 20o1; Tawfiek \& Bagley, 1999. Like other studies, no other ancillary procedures such as DJ stenting were required for our subjects (Mobley et al., 1994; Ashraf et al., 2010). Various studies have reported a success rate of $78-86.7 \%$ for renal and 84.2-88.7\% for ureteric stones (Skolarikos et al., 2006; Miller et al., 1986).

Ghimire et al. (2012) reported a success rate of $96 \%$ for solitary stones which resemble our interpretations. Lingeman et al. (2007) reported that the size of the stone is one of the most important factors that determine the success rate of SWL. In a series of 1910 cases, Newman \& Finlayson (1988) reported a success rate of $80 \%$ for stones o-10 $\mathrm{mm}$ which was reported to decrease to $60 \%$ for stones larger than $30 \mathrm{~mm}$ in diameter. Lalak et al. (2002) reported that the overall stone-free rate was $76 \%, 66 \%$ and $47 \%$ for stones smaller than $10 \mathrm{~mm}, 10-20 \mathrm{~mm}$ and bigger than 20 $\mathrm{mm}$, respectively. Similarly, Abdel-Khalek et al. (2004) reported a stone-free rate of $89.7 \%$ for stones smaller than $15 \mathrm{~mm}$ and $78 \%$ for stones bigger than $15 \mathrm{~mm}$.

All of the stated researchers had a common opinion that the size of the stone is one of the most important predictive factors for the successful outcome of the procedure.The average diameter of the stones in the current study was $13.89 \mathrm{~mm}$. In our study, the success rate was $88.52 \%$ for stones less than $10 \mathrm{~mm}$ and $91.45 \%$ for stones between 10-20 $\mathrm{mm}$. These rates are higher than reports of prior studies. Ghimire et al. (2012) in a study interpreted that the number of necessary lithotripsy sessions increased signif icantly as the stone size exceeded $20 \mathrm{~mm}$. However, we observed a more modest difference in the current study. In addition, the location of the stone is also a very important point that should be considered for treating patients with the urinary stone disease.

While compared with the study report of Preminger et al. (2007) the clearance rate for stones located in the upper, middle and distal part of the ureter our results for different parts of the ureter are more satisfactorily.

Delakas et al. (2003) concluded that distal ureteric stones and stones bigger thanı $\mathrm{mm}$ were the strongest independent predictors responsible for the failure of SWL in patients with ureteric stones. In contrast, we observed approximately the same success rate for stones located in different parts of the ureter. Similar to other studies, gross hematuria was the most common complication of SWL 
(90.05\%) in the present research (Klee et al., 1991).

The types and brand of used apparatus (lithotripter) for SWL in earlier reports were of the separate brand and made, whether the type of lithotripter and its characteristics may also influencing the success rate of lithotripsy is still debatable. The roles of other variables such as technician expertise and the time period of lithotripsy possibly influenced the success rate could not be ruled out. Urolithiasis is a common disease with an increasing incidence and prevalence throughout the world. For selected patients, SWL monotherapy is a safe and effective modality for the treatment of urinary stones. Our conclusions are in contrast to what is believed about the role of SWL in the treatment of the ureteral stones. According to the results of our study, SWL is a good, safe and effective procedure for treating calculi located in any part of the ureter, even the distal segment. In addition, we recommend SWL to treat urolithiasis for any stones (irrespective of composition and size) of the ureter, although the success rate decreases as the size of the stones increase. The criteria for proper patient selection may include the size of the calculus and the number of the stones. However, the location of the stones doesn't seem to have significant effects on the success rate of the lithotripsy.

Acknowledgements:

This study was supported by a grant from the Research Council of the Mazandaran University of Medical Sciences.

\section{References:}

Abdel-Khalek, M., Sheir, K.Z., Mokhtar, A.A., Eraky, I., Kenawy M. \& Bazeed, M. (2004): Prediction of success rate after extracorporeal shock wave lithotripsy of renal stones- a multivariate analysis model. Scand. J. Urol. Nephrol., 38:161-7.

Ashraf, H.S., Heyder, I., Hussain, N., Khan, M.U. (2010): Extracorporeal Shock Wave Lithotripsy;outcome in pediatric urolithiasis. Prof.Med J., 17(4):581-588.

Bihl, G. \& Meyers, A. (2001): Recurrent renal stone disease advances in pathogenesis and clinical management. Lancet 358(9282):651-656

Delakas, D., Karyotis, I., Daskalopoulos, G,, Lianos, E,, Mavromanolakis, E. (2003): Independent predictors of failure of shockwave lithotripsy for ureteral stones employing a secondgeneration lithotripter. L. Endourol., 17:201-205

Dretler, S.P. (1988): Stone fragilitya new therapeutic distinction. $I$ Urol. 139(5):112-147.

Ghimire, P., Yogi, N. \& Acharya, G.B. (2012): Outcome of Extracorporeal Shock Wave Lithotripsy in Western Region of Nepal.Nepal J. Med.Sci., 1(1):3-6.

Ibrahim, A.l., Shelty, S.D., Awad, R.M. \& Patel, K.P., (1991): Prognostic factors in the conservative treatment of ureteric stones. Br. J. Urol., 67:358-361.

Kim, S.C., Burns, E.K., Lingeman, J.E., Paterson, R.F., McAteer, J.A. \& Williams, Jr. J.C. (2007): Cystine calculi: correlation of CTvisible structure, CT number, and stone morphology with fragmentation by shock wave lithotripsy. Urol.Res.,
35(6):319-324.

Klee, L.W., Brito, C.G. \& Lingeman, J.E. (1991): The clinical implications of brushite calculi.L. Urol. 145(4):715-718.

Lalak, N.J., Moussa, S.A., Smith, G. \& Tolley,D.A. (2002): The Dornier compact Delta lithotriptor: the first 500 renal calculi. J. Endourol. 16:3-7.

Lingeman, J., Matlaga, B.R., Evan, A.P. (2007): Surgical management of upper urinary tract calculi. In: Wein, A.J.,et la., ed. Campbell-Walsh Urology. Philadelphia, PA: Saunders;. p. 1431-1507.

Menon, M., Parulkar, B.G. \& Drach, G.W. (1998): Urinary lithiasis: etiology, diagnosis, and medical management In " Campbell's Urology”. Walsh PC. et al., Ed. 7th Edition Washington. USA W.B. Saunders, PP 2661-2733.

McAteer, J.A. \& Evan, A.P. (2008): The acute and long-term adverse effects of shock wave lithotripsy. Semin. Nephrol., 28(2):200213

Middela, S., Papadopoulos, G., Srirangam, S. \& Rao, P. (2010): Extracorporeal Shock Wave Lithotripsy for Ureteral Stones: Do Decompression Tubes Matter?.J. Urol., 76(4): 821-825.

Miller, K., Bubeck, J.R. \& Hautmann, R. (1986): Extracorporeal shockwave litthotripsy of distal ureteral calculi. Eur. Urol., 12:30-35.

Mobley, T.B., Myers, D.A., Jenkins, J.M., Grine, W.B. \& Jordan, W.R. (1994): Effects of stents on lithotripsy of ureteral calculi: treatment results with 18.125 calculi using the Lithostar lithotripter.J. Urol ., 152:66-677.

Moody, J.A., Evans, A.P. \& Lingeman, J.E. (2001): Extracorporeal shockwave lithotripsy. In: Weiss RM, et al., ed. Comprehensive Urology. Mosby International Limited.

Newman, R.C. \& Finlayson, B. (1988): New developments in ESWL.AUA update series. 7:50.

Pearl, M., Nadler, R., Berkowski, E., Chen, C., Dunn, M., Figenshau, R.S., Hoenig, D.M., McDougall, E.M., Mutz, J., Nakada, S.Y., Shalhav, A.L., Sundaram, C., Wolf, J.S. Jr. \& Clayman, R.V. (2001): Prospective randomized trial comparing shockwave lithotripsy and ureteroscopy for management of distal ureteral calculi.J. Urol., 1255-126o.

Preminger, G.M., Tiselius, H.G., Assimos, D.G., Alken, P., Buck, C., Gallucci, M., Knoll, T., Lingeman, J.E., Nakada, S.Y., Pearle, M.S., Sarica, K., Türk, C. \& Wolf, J.S.Jr. (2007): 2007guideline for the management of ureteral calculi.J. Urol.,178:2418-2434.

Sheir, K., Madbouly, K. \& Elsobsky, E. (2003): Prospective randomized comparative study of the effectiveness and safety of Electrohydraulic and Electromagnetic Extracorporeal Shockwave Lithotriptors. J. Urol.,170:389-392.

Singh, O., Gupta, S.S., Girish, G., Aggarwal, G. \& Mathur, R.K. (2010): Influence of Prognostic Factors on the Outcome of Extracorporeal Shock Wave Lithotripsy in Upper Urinary Tract Stone Disease. Int.J.Nephrol. Urol., 2(3):476-48o.

Skolarikos, A., Alivizatos, G. \& Rosette, J. (2006): Extracorporeal Shock Wave Lithotripsy 25 Years Later: Complications and Their Prevention. Eur. Urol. 50:981-990.

Tan, P.K., Tan, S.M. \& Consigliere, D. (1998): Ureteroscopiclithoclast lithotripsy: a cost effective option. JEndourol.,12:3414.

Tawfiek, E.R. \& Bagley, D.H. (1999): Management of upper urinary tract calculi with ureteroscopic techniques. Urology, 53:25-32.

Wilkinson, H. )2001): Clinical investigation and management of patients with renal stones. Ann. Clin.Biochem.,38:180-187. 